\title{
Managing radical innovations in established companies
}

\section{Tuomas Heikkinen, Pekka Belt, Matti Mottonen, Janne Harkonen* and Harri Haapasalo}

\author{
Industrial Engineering and Management, \\ University of Oulu, Finland, P.O. Box 4610, \\ FI-90014 University of Oulu, Finland \\ E-mail: tuomashe@gmail.com \\ E-mail: mjmotton@gmail.com \\ E-mail: pekka.belt@gmail.com \\ E-mail: harri.haapasalo@oulu.fi \\ E-mail: janne.harkonen@oulu.fi \\ *Corresponding author
}

\begin{abstract}
Established companies need to take several aspects into account when considering the management of radical innovations and must simultaneously ensure the profitability and functioning of the existing business. The main contribution of this study lies in exploring how radical and incremental innovations are separated and managed. The article intends to clarify how companies can evaluate ideas, organise decision-making, utilise external parties optimally, and organise innovation activities while ensuring adequate linkages to existing business processes. This study analyses the practical implementation of innovation activities in a leading telecom company with advanced practices for managing innovations. The case company has established a separate innovation unit and defined a process for radical innovations. Linkages to other existing development processes are strengthened by including key personnel from these processes in the company's innovation process. These arrangements aid in acknowledging numerous aspects presented in the literature in conjunction with radical innovations.
\end{abstract}

Keywords: radical innovation; incremental innovation; innovation management; corporate venturing; management practice; comprehensive innovation management.

Bibliographical notes: Tuomas Heikkinen received his M.Sc. (Tech) in Industrial Engineering and Management from the University of Oulu, Finland. He has extensive experience at managerial levels from several companies in the ICT sector. Currently he is finalising his doctoral dissertation. His research interests cover innovation management, business models and company strategy.

Pekka Belt received his MSc in Engineering in 1984 and his Dr (Tech) in 2009, both from the University of Oulu, Finland. He has extensive industrial experience at managerial level from several electronics enterprises, covering company functions from technology development to international marketing. His research interests include entrepreneurship, entrepreneurship education, product development and international marketing. He has authored and co-authored over thirty journal articles and also a number of other publications.

Matti Mottonen received his MSc in Engineering in 2006 and his Dr (Tech) in 2009, both from the University of Oulu, Finland. His research interests cover product development, Innovations, requirements management and high-tech internationalisation. He has authored and co-authored over twenty journal articles and also a number of other publications. Currently he is an entrepreneur aside his research activities.

Dr Janne Harkonen received his Bachelor's degree (1st Class Honours) in Engineering Business Management from University of Greenwich in the UK and both his M.Sc. in Process Engineering and Dr (Tech) in Industrial Engineering and Management, from the University of Oulu, Finland. He has also studied in the University of North Carolina at Wilmington, USA. He has experience working in the IT and environmental technology 
industries. Currently, he is a senior research fellow at the University of Oulu in Finland. Dr Harkonen has authored and co-authored over fifty journal articles, and also a number of other publications.

Harri Haapasalo is a Professor of Product Management at Industrial Engineering and Management, University of Oulu in Finland. He has three main areas of research; one in product management, product development, second one in area of complex systems management, lean construction and business models, and third in technology management and innovations. He has been very active in obtaining research projects, and active in journal publications. His list of publications contains more than 200 international items. He has supervised more than 20 doctoral theses and been external examiner for more than 20 doctoral dissertations.

\section{Introduction}

Today, most industries are characterised by technological and market uncertainties. For companies to be successful, they need to be both effective in their existing business and, at the same time, innovative in building future success (He and Wong, 2004; Trott, 2002). This poses challenges for management, as these two goals of streamlining processes vs. creating an environment to nurture innovation require the organisation to have quite a different set of capabilities and processes, as well as a different culture (Christensen, 1997; Govindrajan and Trimble, 2005). Therefore, it is vital to understand the practices that are required for developing radical innovations while simultaneously succeeding in the main business - that is, possessing the right balance of exploration and exploitation capabilities (Cohen and Caner, 2016; March, 1991).

Managing radical innovations can be difficult, even for successful and innovative companies with considerable resources and technological capabilities (Alsan and Pasiner, 2009; Christensen, 1997). Several impediments exist in regard to the development of radical innovations, including excessive focus on current customers (Christensen, 1997), the suppressing influence of the main business on new initiatives (Burgelman and Sayles, 1986; Christensen, 1997; Govindrajan and Trimble, 2005; 
Markides, 1999), and the constrained mental model of managers (Bettis and Prahalad, 1995; Prahalad and Bettis, 1986).

Large companies typically organise their substantial established businesses into strategic business units (SBUs), and companies also use the terms segmentation and divisions. These units have a clear strategy and defined product/customer segments. SBUs have business responsibility and aim to keep their expenses under control without losing their focus unnecessarily. However, operational product development and the research supporting SBUs' own product development are typically the unit's responsibility. In case the company has one dominant business that cannot be feasibly divided into divisions, the business is often divided into key processes. These key processes are then assigned to responsible managers. The management of large companies typically understands that the company also requires a separate unit that has a role in ideating and developing more radical innovations and new business opportunities (Leifer et al. 2001; Slater et al. 2014). This occurs as the accountable units or key processes are forced to streamline their activities, and the activity culture does not support the radical development in an optimal manner. The corporate culture has also been found to be a particularly important driver for radical innovation (Tellis et al. 2009). The need for control versus the need for flexibility involves tension that is necessary to address (Deshpandé et al.,1993; Quinn and Rohrbaugh, 1983. This is why a separate innovation unit or process is necessary. The most potential innovation/development functions that are not well suited to the SBUs or key processes can be found here, meaning that an innovation unit can be vaguer than SBUs or key processes, allowing for the necessary degrees of freedom (Koberg et al. 2003), particularly to enable radical innovation. Due to the nature of the beginning, the critical phase of innovation, and activities such as selection and funding of projects, they logically fall into the innovation unit's domain. Nevertheless, these matters are traditionally discussed as separate entities in the literature. The selection of innovation projects needs alternative practices outside the "normal" decisionmaking channels (Bessant et al. 2010). Also, innovation can be stimulated by the means of effectively reviewing proposals to fund projects (Rice et al. 1998). However, the separation of innovation projects and funding of projects have not been adequately described by the previous literature.

Previous research has provided versatile viewpoints regarding the management of radical innovations. However, there is a clear need to combine these viewpoints in practice at the company level. It is important to better understand how the management of radical innovations can be successfully combined with other development activities to optimally serve business needs. Perspectives are needed on how to organise radical innovations and ensure that cooperation between SBUs/key processes and the relevant interfaces of their development activities so that the whole entity is favourable for the company.

This study analyses the innovation practices of a large established company that utilises a separate innovation process to develop radical innovations and has a need to standardise decision-making related to new radical business ideas. The analysed significant Scandinavian telecom company has organised its key processes and assigned responsible managers. The analysis focuses on the radical innovation practices that the company has created based on years of organisation wide consideration and experience. This study also considers the extent to which the company's solutions are in line with the views presented in the literature. In particular, there is an attempt to clarify the roles of the innovation process, and the selection and funding of projects in managing radical innovations, as all these activities differ from those carried out in the mainstream business. The study entails 
an extensive literature analysis and an examination of the practical implementation of innovation activities while also identifying related challenges. The abovedescribed aim can be condensed into the following research question:

$R Q$ What type of challenges are encountered regarding radical innovation in an established company applying systematic innovation practices, and how are they overcome?

These research questions are approached by interviewing the key personnel responsible for both radical innovation and the interlinking processes. The literature is analysed in regard to the discussed topics. The paper describes the solutions implemented by the Scandinavian telecom company, as well as the related challenges, and it compares the solutions to those presented in the literature. An attempt is also made to identify the potential pitfalls of applying systematic innovation practices.

\section{Literature review}

Radical innovations are classically defined as having a high degree of novelty, as opposed to incremental innovations, which are related to the enhancement of the company's existing offerings or processes (Dodgson et al., 2008; Tidd, 2001). In addition, the terms disruptive (Christensen, 1997) and discontinuous innovation (Tidd and Bessant, 2009; Tushman and Anderson, 1986; Utterback, 1994; Veryzer, 1998) are used to emphasise the revolutionary consequences of competition. Other factors related to whether innovation should be designated as radical include whether the company is incorporating technology that is clearly a risky departure from the prevailing practices, as well as the extent of the changes required by the company (Ettlie et al., 1984). Norman and Verganti (2014) use seeking the highest hill as a suitable metaphor for radical innovation, compared to incremental innovation, which is attempting to reach the highest point of the current hill. Another way to express this is by stating that when radical innovation occurs, the product characteristics are in flux (Abernathy and Utterback, 1978). Nevertheless, Green et al. (1995) also point out that radicalness has multiple dimensions involving technological uncertainty, technical inexperience, business inexperience, and technology cost.

Large established companies are seen as more likely to fail in radical innovation as their capabilities for incremental innovation reduce the effectiveness of their attempts to exploit radical innovation (Henderson, 1993). A company's innovation capacity and methods are critically dependent on its stage of evolution (Abernathy and Utterback, 1978). The findings by Ettlie et al. (1984) also suggest that top management support in the innovation process is necessary for radical innovation, while centralised decision-making is needed. Radical innovations, product or process, tend not to receive ready acceptance when certain systematic stage has been reached (Utterback and Abernathy, 1975). Most radical innovations take place with new entrants surfacing amongst the established competitors, whose resources and focus are geared towards exploiting the existing technologies (Utterback and Suárez, 1993). Established companies tend to rely on the existing internal knowledge of markets and technologies, and they attempt to stretch their competencies to enter into radical product or process areas where they face a new set of challenges (McDermott and O'Connor, 2002). However, the use of radical innovation hubs, for example, is seen as a way for mature companies to oversee and nurture radical innovation, the hubs supporting the reduction of uncertainties and unnecessary bureaucracy (Leifer et al., 2001). 
Besides product, service, and process innovation, other types of innovations are presented in the literature. These include innovations related to new market positions, business models, new business paradigms, product platforms, and system-level architecture (Abernathy and Utterback, 1978; Francis and Bessant, 2005; Gawer and Cusumano, 2002; Henderson and Clark, 1990; Johnson et al., 2008; Tidd and Bessant, 2009).

\section{The innovation process and the beginning of innovation}

Innovation consists of the entire process of converting an idea into practical and commercial use. Traditionally, innovation processes have been understood to be driven by either research and technology or market demand - that is, technology push or market pull (Tidd and Bessant, 2009; Trott, 2002). The application of a global innovation process is also seen as a source of achieving higher-value innovations at lower costs, whereas Santos et al. (2004) argue that utilising globalisation for innovation activities lags behind other company functions in terms of importance.

In presenting the development of innovation processes, Rothwell (1992) shows the shifts in how innovation is perceived at different times and the need for frameworks, but he also indicates how challenging the front end of innovation can be. The fuzziness of the front end favours certain traits, but specific tools or methodologies may also support working when certain ambiguities prevail. For example, playfulness, simulation, and modelling have been described as best characterising the nature of innovation processes (Dodgson et al., 2005; Shrage, 1999). In addition, the discovery-driven planning approach recognises the unknown nature of the future and proposes that assumptions are made while the facts are revealed during the process (McGrath and MacMillan, 1995). The following proposition is, therefore, developed:

P1. An innovation process ought to be organised sensibly in well-established companies, but should simultaneously allow necessary lighter characteristics such as playfulness.

The beginning, which is the critical phase in the innovation process, is widely referred to as the fuzzy front end, especially in the context of new product development (Khurana and Rosenthal, 1997; Koen et al., 2001; Zhang and Doll, 2001). The fuzzy front end matters, particularly because it often entails the selection of the ideas to be developed further. The fuzzy front end typically covers activities from the generation, screening, and selection of the best ideas to concept development and then business case analysis, and it often even includes concept testing (Cagan and Vogel, 2002; Cooper, 2001; Khurana and Rosenthal, 1997; Koen et al., 2001; Nobelius and Trygg, 2002; Trott, 2002). It is, however, necessary to note that research and development (R\&D) projects tend to evolve in stages (Contractor and Narayanan, 1990) and possibly as logical extensions of projects. $R \& D$ activities also involve a high degree of uncertainty and serendipity, which are factors that cannot be ignored (Niosia, 1999). In addition, the interests of the $R \& D$ personnel have a strong influence on the selection of priorities (Adams, 1983).

Managers are typically more familiar with the later innovation stages, during which activities are defined and the processes and procedures before commercial appearance exist. However, the true benefits of new ideas are seen to emerge from the fuzzy front end of innovation (Gassmann and Schweitzer, 2014). The fuzzy front end is emphasised as critical because success or failure is often inaugurated before the more defined activities and due to companies lagging in regard to their innovation 
processes (Frishammar et al., 2011). Thus, even though it is necessary to understand innovation processes thoroughly, starting from idea generation, Van den Ende et al. (2014) point out that to support the front end of innovation, it is necessary to improve our innovation process understanding, particularly for the benefit of idea management systems.

The fuzzy front end may include sequential phases with evaluation points between the phases, as in the widely known stage-gate model by Cooper (2001). The fuzzy front end can also be viewed as iterative (Koen et al., 2001). Some authors emphasise the differences between strategic-level elements and project-level activities (Khunara and Rosenthal, 1997) or the context-specific nature of the process (Nobelius and Trygg, 2002). The typical criteria for evaluating new innovations in a stage-gate process consist of market factors, technical feasibility, financial suitability, and the question of whether the innovation is well suited to the company's strategy (Kinnunen et al., 2011).

Although the fuzzy front end can be viewed as the early activities of the typical new product development process, Veryzer (1998) suggests that the process for discontinuous innovations can be handled as a distinct process preceding the new product development process, which is more suited to incremental innovations. O'Connor et al. (2008) propose that radical innovations should be managed in three phases, each requiring different kind of capabilities. The first phase is discovery, which equates to the fuzzy front end. This is followed by the incubation phase, which focuses on nurturing an immature innovation. The final phase-acceleration-is responsible for transforming the radical innovation initiative into a business that is ready to begin operating, for example, in an established business unit of the company (O'Connor et al., 2008). However, Reid and De Brentani (2004) argue that radical innovations occur in the organisation in a variety of ways, originate from the external environment, and are initiated by individuals acting as boundary spanners and gatekeepers for the company. Hence, the essence of the fuzzy front end is seen to lie in the process of identifying, understanding, and acting on emerging patterns whilst a series of decisions of a different nature take place (De Brentani and Reid, 2011). Openness also seems to have a role in the fuzzy front end, as openness competence and uncertainty reduction are closely related and relevant to innovation success (Thanasopon et al., 2016; Chang et al., 2012). The following proposition is developed:

P2. The beginning of innovation - the fuzzy front end, consists of a necessary part of the innovation process and supports both incremental and disruptive innovations, and hence must be handled by an established company in a manner that enables emerging patterns to thrive regardless of their later handling.

\section{Sources of innovation}

One major question related to innovation management concerns the sources of innovation. For example, the work by von Hippel recognises customers as the main source of innovations, especially lead users, who identify the future needs before the rest of the market (1988). Conversely, a tight customer focus often impedes disruptive innovations from developing, as the needs of current customers tend to result in incremental innovations based on the company's existing products (Christensen, 1997). Customer-driven innovation can, however, span numerous generations of 
product lines, as shown by the IBM turnaround from inflexible main frames to innovative customer segmentation by providing solutions that the customers needed (Meyer et al., 2005). The sources of innovation may also involve other forms of external cooperation, such as the use of distributors or intermediaries (Biemans, 1991; Shaw, 1988; Stasch et al., 1992), the integration of suppliers/vendors into NPD (Bonaccorsi and Lipparini, 1994; Clark, 1989; Comer and Zinger, 1997; Stasch et al., 1992), and dealings with overseas sister companies (Sowery, 1990; Stasch et al., 1992). Nevertheless, regardless of the variety of innovation sources, if a company does not have the capacity to process the innovations coming to its pipeline, the influx can create bottlenecks and slow the overall innovation process (Chesbrough, 2017).

Chesbrough's (2003) concept of open innovation places emphasis on the external environment, while the innovation process has traditionally been seen more as an internal operation. Openness has, however, been involved in company innovation activities for decades (Dahlander and Gann 2010; Trott and Hartmann, 2009). The literature also refers to openness capability, which is an organisational capability that can increase radical innovation performance in established companies based on the ability to search sources of radical innovation with an external, distant, and wide orientation (Chang et al., 2012).

P3. The sources of innovation have relevance for the innovation process by having a potential relation to whether the innovation will become disruptive, or whether it remains incremental. The capacity to process the innovations is, however, essential for both innovation types.

\section{Managing radical innovations \& selection and funding of projects}

The mental model of managers is often confined by a company's current business model, potentially impeding the development of radical innovations (Bettis and Prahalad, 1995; Doz and Kosonen, 2010; Hamel, 2000; Hamel and Prahalad, 1994; Prahalad and Bettis, 1986; Tikkanen et al., 2005). Tripsas and Gavetti (2000) conducted a case study on the response of Polaroid Corporation's shift from analogue to digital imaging. Polaroid was able to shift from technology-driven to more marketdriven but was unable to shift its managerial cognition related to the business model. Chesbrough and Rosenbloom (2002) found that a successful company had difficulties in identifying the potential of new ventures that required business models that differed from the company's dominant logic.

The culture and values of an established organisation can hinder initiatives that require a completely new culture and values. In addition, new and initially small initiatives are easily suffocated by the existing bigger business. Hence, it may be sensible to consider establishing independent organisational units when focusing on strategic initiatives that require a different kind of business model (Christensen, 1997; Govindrajan and Trimble, 2005; Markides, 1999). Building a new organisational unit may be sensible, especially when a new innovation are not well suited to the organisation's processes and values or it is not possible to utilise the existing organisational knowledge (Burgelman and Sayles, 1986; Christensen, 1997; Tidd and Taurins, 1999). However, O'Reilly and Tushman (2004) emphasise the importance of close top management links between the new initiative and the main organisation, and Leifer et al. (2000) argue that most radical innovation projects still benefit from interaction with the mainstream organisation. Leifer et al. (2001) propose that large established companies could use innovation hubs to take care of the fuzzy front-end part of the innovation process. These innovation hubs can act as knowledge centres. 
O'Connor and DeMartino (2006) argue that capabilities related to radical innovations, discovery, incubation, and acceleration are difficult to achieve with a single organisational structure. According to O'Connor et al. (2008), managing radical innovations should be viewed in companies as an own function, compared with innovation to marketing, which has evolved from an activity to an own function. According to Forés and Camisón (2016), the company's capabilities have a positive direct effect on radical innovation performance, whereas the construction of a diverse and rich internal knowledge base through the internal knowledge creation is critical for the development of the necessary capabilities.

The selection and funding of projects is critical for innovation. In the corporate venturing model, innovations are typically created in relatively independent business units within companies and are either merged into the existing organisation later or an exit is arranged (Burgelman, 1983; Burgelman, 1994; Tidd and Bessant, 2009). The relationship between a new venture and an existing organisation can be described by two attributes: organisational (structural and cultural) and financial links (Thornhill and Amit, 2000; Wolcott and Lippitz, 2007). Thornhill and Amit (2000) argue that closer organisational rather than financial tights correlate with new venture success, while Wolcott and Lippitz (2007) suggest that radical innovations need to be managed relatively independently of other organisations and with adequate funding. Michalski (2006) presents seven success factors for creating radical innovations through corporate venturing, as well as supporting certain autonomy and emphasising competencies. In corporate venturing, funding can be organised using the venture capitalist model, whereby the company provides seed funding and the stages that follow are funded based on evaluations (Rice et al., 2000). According to Covin et al. (2015), regardless of internal corporate venturing being somewhat poorly understood, these activities can facilitate the recognition of product-market opportunities, the development of new organisational capabilities, the discovery of new technological possibilities, and the creation of new strategic trajectories. The following propositions are developed:

P4. The culture and the organisation itself affect the possibilities the innovations have. Hence, a separate organisational structure can help in supporting those initiatives that require a different logic, but necessitate adequate interaction with and linkages to the core business.

P5. Corporate venturing is one example of mechanisms to select and fund projects, one that enables established companies to nurture radical innovation and avoid unnecessarily early rejection, due to differing business models, cultures, values, or process or knowledge incompatibilities, while maintaining a relationship with new ventures and facilitating the recognition of opportunities.

\section{Research process, data, and methods}

The study was conducted to clarify the roles of the innovation process, particularly the beginning of innovation, and corporate venturing in managing radical innovations. A qualitative study design was chosen, as little is known about the combination of the early stages, and corporate venturing as an aspect affecting radical innovation in established companies. The rationale of the study is to capture the circumstances, conditions, and related decisions in the realm of radical innovations in established companies. The specific focus is on separating innovation processes to promote radical innovations, and funding of projects. 
Figure 1 illustrates the research process that is utilised in this study. The literature enabled the grounding of the study on the relevant extant research and clarification of the discussion on managing radical innovations. Special attention was paid to the practical perspectives of established companies in regard to the organisation of their innovation activities. An analysis of the literature provided perspectives on how the matters under discussion are understood, how organisations address these matters, and how different authors have contributed to the discussion. The case company was selected based on the possibility of having access to such a large and established company that has relevant innovation practices.

Although focusing on a single case is sometimes considered problematic in terms of generalisability, the research design also has its advantages. Following the inductive logic on the topic, we attempted to facilitate future studies that can test the findings and elaborate them further (Eisenhardt, 1989). An advanced company with established practices for its innovation activities was identified, and its practices were analysed. The possibility of triangulating between different data sources provided certain advantages, as process descriptions, interviews, observations, and company documentation were used. The descriptions in the literature were also cross-analysed against the practices identified during the empirical analysis.

The empirical research was realised in two phases. First, the company's development activities were clarified by conducting 20 interviews covering all the relevant processes, including portfolio management, research, innovation, requirements engineering, strategy, and business development. In the second phase, three additional interviews were conducted, concentrating in particular on the innovation process. The interviewees were selected carefully to cover all the people who would be sufficiently knowledgeable of the topics and have adequate relevant exposure and experience. The interviewee titles for the 20 initial interviews were discipline owner (8), delivery capability manager (9), process development manager, portfolio manager, and senior manager. The interviewee titles in the second phase were senior principal innovator, senior research manager, and concept owner. The roles of the three latter interviewees are: an internal venture capitalist developer of start-ups; person responsible for the design and road mapping of new product concepts and technologies; and a person globally responsible for a concept that delivers internal requirements for product development. The interviewees represented the innovation process, research, order delivery process, product process, discipline management, and each individual sub-discipline that the company has developed to ensure delivery capability. The interview topics covered the industry value chain, the internal value chain, the innovation process, innovations generally, the innovation process at the analysed company, idea generation and management, project proposal preparation, idea verification and field trial, portfolio management, the innovation unit's role, innovation-related challenges, external knowledge sources, and intellectual property-related issues.

The interview analysis entailed examining the transcribed interview data and coding and categorising common themes to assess any patterns in a descriptive manner (e.g. Saldaña, 2009). All of this was supported by the company's internal documentation to complement the interviews and allow for triangulation. The company practices were thoroughly analysed, described, and scrutinised.

\section{[Please insert figure 1 here]}

Figure 1. Research process 
The research utilised a semi-structured thematic interview approach (Merton et al., 1990). The interviews were conducted informally in a qualitative manner, allowing the interviewees to explain and clarify the topics as entities. Finally, the interviews were transcribed and analysed. The researchers were involved in several research projects with the case company, enabling excellent access to all the key experts to be interviewed. Hence, the possibility of having access to a significant, well-established, globally operating company was among the motivations for selecting this company; however, the more important factors were the existence of a suitable setting for the early stages of development, and corporate venturing.

\section{Case company}

The case company is a major Scandinavian telecom company with tens of thousands of employees. The company operates globally and has multiple sites in numerous countries. The company's business is divided into key processes, which are assigned to responsible managers. The main processes include order delivery, product creation, innovation, and research. The internal processes are streamlined to enable maximum delivery capability. To maximise delivery capability, certain disciplines are developed to ensure the acknowledgement of needs of manufacturing, the supply chain, and after sales during product development.

The company has a strong background in internal research and product development practices. Previously, it mainly provided hardware equipment, but the focus has shifted increasingly to include solutions covering software services and system integration. The market environment has put pressure on the company to find new revenue sources, as the main market is maturing.

Today, the company places great emphasis on cooperation with universities, research institutions, and standardisation bodies, as they provide important knowledge for innovations and product development. The company has also considered the possibilities of the open innovation approach to better utilise external input.

The case company has established a new Innovation unit that is responsible for managing radical innovations. At the time when the company was considering its innovation policies, it conducted benchmarking on other companies in the ICT sector. The company has established a functional benchmarking relationship with one major company in the sector.

\section{Results and analysis}

The case company has a clear need to standardise decision-making related to new radical business ideas. Figure 2 illustrates the innovation process and related organisational processes for product/solution portfolio management, research, and product development. The innovation process manages the activities related to how ideas can become new businesses. The source of ideas for an innovation process can vary. The senior principal innovator described the innovation process as follows:

The innovation process is a process about ideas, and it describes how ideas can end up becoming businesses. Ideas can originate from any individual or can be initiated collectively. Innovations are not only technological but can also be business innovations or market innovations. Also, idea refining is a vital part of the process all the way until it becomes a business and it has been productised. 
The product development process can be interpreted as the end phase of the innovation process. However, in the case of radical innovations, the innovation process and product development process are parallel processes.

The case company makes a distinction between incremental and radical innovations. The product development process handles incremental innovations that can mean, for example, upgrading an existing product or platform development. The innovation process handles radical innovations that can mean new concepts in markets, technologies, or business models.

\section{[Please insert figure 2 here]}

Figure 2. Innovation-related processes in the case company

The research process and innovation process have not been integrated formally, neither is the link between them close. However, when an innovation involves developing a business based on a certain technology, the innovation process can be seen as a continuation for the research process.

The product development process may be initiated after the innovation process. In some cases, when an innovation requires product development activities, innovation and product development processes can be parallel.

If during the innovation process, it is estimated that an idea has enough potential, the idea will be handed over to the product/solution portfolio management process and will become the responsibility of the company's business units. The portfolio management process is used to manage products and solutions.

Finding 1. Separating innovation processes, those resulting in incremental innovations, and those of radical innovation can provide a practical solution for an established company to separate activities not suited for key processes, and to clarify related decision-making, while retaining linkages to company processes.

\section{The innovation process}

The innovation process includes four sequential phases: idea generation, proposal preparation, idea verification, and field trial. The field trial is optional and is not always carried out.

Idea generation: Ideas may originate from several sources, such as customer feedback, university cooperation, innovation workshops, or internally from personnel. The case company has implemented a specific tool for managing innovation ideas. The tool is tailored from a commercial tool. All employees can feed their ideas into this tool and comment on the ideas submitted by others. Most of the ideas are generated outside of the formal innovation process. The internal ideas for technological innovations typically originate from the product development personnel, while the customer and marketing organisation is a source of ideas for solving customer problems.

One example of radical innovation in the analysed company involves the size of the base stations, which are the company's products. Previously, cranes were necessary for base station installations due to the sheer size of the products. The company used to redesign the entire base station cabinet from scratch for each new product, including new application-specific integrated circuits, and the radio frequency processing unit. The customers preferred smaller products, and the 
personnel were trying to find ways to make the products smaller. The change of mindset in regard to product design in the form of introducing Design for Logistics (DfL) product design principles was the key to getting rid of the old, unnecessarily large products. A senior manager described the situation: "DfL product design principles enabled us to get rid of the old type of cabin, as the product was now designed with the requirements of the logistics in mind and was not designed from scratch every time." The new products did not require a cabinet but could still be fitted into one or to any standard rack. The product modules were designed to be weather-proof ones that could be installed indoors or outdoors, stacked as needed, installed on a pole, or mounted on a wall. The senior manager stated, "It was the mindset of design principles that was the key and also supported the culture of internal collaboration." In this case, it was the company personnel who came up with the idea of focusing on the design principles.

The innovation unit is responsible for naming a dedicated stakeholder for each idea. Often, an individual idea is discussed, peer-reviewed, and refined at innovation round-table discussions or the innovation unit's internal review meetings. The innovation round-table is a peer review that includes interested company personnel. The innovation unit cooperates with the relevant stakeholders within the company. In the DfL innovation case, the company utilised internal review meetings, and multiple key people had a role before launching the principles, which was followed by extensive training. When an innovation relates to developing a business based on technologies, the work is typically conducted with the research unit personnel. In the case of business model development, the personnel responsible for strategy and business development are included. An interviewee described the role of the innovation unit as follows:

We have a special task to look outside existing business and customers, as well as existing customer requirements. In practice, it can mean developing something that customers are not demanding at the moment or developing something for totally new customers. We are, thus, willing to take more risks.

Finding 2. The separate innovation process intended to support the creation of radical innovations has a specific role in established companies. However, ideas can also be generated outside the process and can originate from versatile sources.

The proposal preparation phase prepares business plans for new ideas. The case company has adopted a venture capitalist model for this phase, whereby the internal Innovation board, which consists of senior executives, has the mandate to decide whether the idea will receive the finance to continue as an innovation project. The venture capitalist model includes defining value for customers, uniqueness, competition situation, estimated development time, development costs, and which architectures/platforms are to be used. A senior manager commented on the venture capital model as follows:

In internal programmes, the company invests strategically to support our own business, but the slow decision-making can become a problem, and the current financial situation also has an impact. External programmes can be more flexible in finding investments for ideas that are more likely to be disruptive, and yes, they can be much more flexible.

In the DfL innovation case, the company invested internally as a significant development project. 
The criteria that the analysed company uses to evaluate ideas are shown in Table 1. The ideas are prioritised based on their attractiveness, feasibility, and time to revenue, and the best ideas are transformed into innovation projects.

Table 1. Prioritisation criteria for new ideas

\section{[Please insert table 1 here]}

Finding 3. Using corporate venturing as the model for selecting and funding projects supports nurturing innovations while maintaining business related criteria with relevant decision points to aid decision-making.

Idea verification and field trial: The sustainability of an idea is verified during these phases. This can mean creating a demo of the idea. In the field trial, the idea is tested with a customer. The idea of DfL design principles was demonstrated internally to show that it can be done and to secure adequate commitment. Certain change resistance was evident, but extensive training helped to curb the biggest resistance. Even though the field trial phase is optional, in practice, the innovation board requires at least one interested customer to be involved in the project for a go-ahead decision. After a demo is ready, the customer inspects it and learns how it works. The customer can present the demo to his or her customers for their assessment. Customers may also collect feedback from specially formed end-user focus groups.

Finding 4. Demonstrating an idea acts as a vehicle for commitment. However, requiring field trial to support decisions on selecting projects to be funded in an attempt to reduce risk entails the evident risk of failure to recognise value in new concepts due to an attachment to existing customers.

\section{Guiding principles for innovation activities}

The case company's innovation unit focuses mostly on large innovations, as the company has streamlined its processes to master high-volume business. One of its targets is to support innovations that bring in some $€ 500$ million in turnover in two to three years. Roughly one idea out of four hundred achieves this goal.

The innovation unit, together with the strategy and business development units, defines focus areas, especially to seek innovations. These focus areas have been defined to cover megatrends with growing business potential. However, a clear customer need is required, and the case company must have the necessary assets and capabilities. Together with external parties, the innovation unit prepares business environment scenarios and tries to identify weak signals.

One of the key principles is to fail fast and cheap. If there is no perfect match, then an idea is quickly terminated. Ideas are not transferred into product development if the real business value is not known.

If an innovation is internal, the original innovator receives a moderate reward. The main benefit for the innovator is that he or she can have a role in the realisation of the idea once it has secured financing.

Those in charge of the innovation projects attempt to find customers who are sufficiently motivated to participate and collaborate at their own expense. The case company believes that customer motivation comes from the project results, which can create better business opportunities, make their processes more efficient, and/or 
enable the creation and capturing of more value. Access to new markets may also be an incentive, especially for small companies that participate in innovation projects.

Finding 5. Particular innovation unit, responsible for the critical early stages of innovation in an established company may support decision making while seeking for disruptive innovations. Necessitating a clear customer need, however, risks blurring the distinction to incremental innovation.

\section{External cooperation}

Customers are the most important external stakeholder group for the innovation process of the case company. First, customers are important sources of ideas both in terms of revealing their development plans for the future and by providing the main channel for the case company to understand the needs of the end customers. Second, the case company views it as paramount for customers to become involved in the innovation process right from the beginning; consequently, it is a requisite for innovation projects to have a committed customer involved. The case company organises theme-specific innovation workshops with customers. The case company also considers granting access to its innovation tool for customers once the collaboration model is defined.

The case company has a strong and established cooperative relationship with some other firms. Representatives from these partners are involved in the innovation process due to the swapping of ideas. However, the innovation tool has not been opened to these partners. The main focus of the innovation process is on the case company's internal activities and its direct customers.

The case company has entered completely new markets outside of its traditional business domain when existing technology and product bases are utilised by applying them to completely new areas. Partners are typically involved when entering new business areas in order to gain required technical and marketing know-how.

The case company is also interested in utilising innovations made outside the company. It is company policy to follow the development of interesting start-ups and acquire them once they are mature enough. Universities also act as partners to the case company. This cooperation mostly covers research projects that can provide potential innovations.

Development work is often conducted with competitors; this is typically done in regard to research projects that are in the early phases of the development chain, in cases of innovations concerning non-core technologies or production processes, and when developing standards.

The case company regards internal and external social networks as having great importance. It is the duty of the innovation unit to promote involvement in these networks. The case company even takes part in some research projects purely to obtain valuable contacts through participation. The company is also involved in some virtual networks.

Finding 6. Involving stakeholders and external partners, as well as certain openness can be beneficial for obtaining idea input for an innovation process.

\section{Innovation process challenges}

Regarding the screening phase for new ideas, one challenge arises from the large number of ideas to be screened and refined. An interviewee commented on the 
screening phase as follows: "One of the biggest challenges of [the company] is the screening and systematic refinement of new ideas from a huge number of people. If the wrong person is evaluating an idea, even a brilliant idea may be discarded." As the company has tens of thousands of employees, it is laborious to undertake a proper evaluation of every idea. Unfortunately, the first evaluation of new ideas is heavily based on the understanding of the first individual evaluator.

The number of ideas coming from employees is large compared to the capacity of the innovation process. Employees are assumed to have more potential for innovation, should the process be capable of handling the ideas. Conversely, the excessive burden of daily tasks does not leave much room and energy to develop and share new ideas.

The case company has been unable to create clear decision rules for balancing risk-taking for renewal with the certainty required to make investments. It is understood that innovations inherently involve risk-taking; yet, some reluctance exists, and the current rules emphasise revenue calculations and certainty.

The priority of innovative activities is heavily dependent on the prevailing financial situation. Tougher times typically make the evaluation criteria stricter for innovation projects. Customer involvement is not officially mandatory but is required in practice for an innovation project to get a go-ahead decision. Especially during difficult times, an innovation project does not even have an opportunity to proceed to the verification phase without the involvement of a customer.

The case company finds it challenging to attain a high level of customer involvement. It is also difficult to identify any hidden risks related to customer involvement. An interviewee described the risk of customer involvement as follows:

Customers may have serious problems that are not visible. For example, a customer may be in a very weak financial position, and is desperately betting on some new innovation to solve some problems. In these situations, the customer may be very active in supporting the innovation process, but after some relatively small occurrence, they may be forced to withdraw. Hence, one big challenge is to identify hidden risks that may place the company in an awkward position.

The strong emphasis on customer cooperation in innovation activities also has its drawbacks, as the existing customers are often not in the best position to give guidance regarding future innovations. Moreover, the current mindset within the company is to consider the needs of the customers within the present-day business sector. In addition, getting an adequate commitment from a customer in another business sector can be challenging.

The case company has taken cautious steps in opening its innovation process to partners and other parties. The innovation process is developed mainly to support innovations created within the case company, making it deficient in terms of utilising ideas from partners.

IPR issues have become increasingly important both when considering acquisitions and when selling innovations. The case company sees its patent portfolio as the main instrument for balancing and outsourcing innovations. The company utilises research and innovation results in several ways, also those that are not considered in the company's own product development. Due to the commonness of juridical disputes, especially in North America, IPR issues are regarded as one of the main challenges for the successful creation of innovations in cooperation with other parties.

Table 2 summarises the challenges that the case company faces in regard to its innovation activities. 
Table 2. Challenges encountered in relation to innovation activities

\section{[Please insert table 2 here]}

Finding 7. The challenges encountered in regard to radical innovation in an established company involve idea generation and screening, decision-making, customer cooperation, and IPRs.

Finding 8. Considering the dynamics of separating innovation processes and making a distinction between activities aiming towards disruptive and incremental innovation, and the dynamics of the selection and funding of projects - the corporate venturing approach, may provide perspectives for innovation management in established companies. The realities of established companies necessitate a certain carefulness and compatibility with other company processes, affecting the exploitation of radical innovations under the company umbrella.

\section{Discussion}

This study provides a level of description regarding how an established company has organised its innovation practices to address both radical and incremental innovations. The innovation process is organised alongside other key processes that are assigned to responsible managers. A separate innovation process has been established not only to standardise innovation-related decision-making but also to better enable exploration outside of the existing business and customers and develop something new in an environment that allows for more risk-taking.

Attempting comprehensive innovation management may entail some challenges. The challenges encountered when applying systematic innovation practices mostly relate to idea generation and screening, decision-making practices, customer cooperation, and IPR. Due to its large size, the analysed company finds it laborious to undertake an adequate and unbiased evaluation of every idea. The company has been somewhat unable to create clear decision rules for balancing the risk-taking and certainty required to make investments. In addition, customer involvement is not officially mandatory for the acceptance of ideas but is required in practice for an innovation project to get a go-ahead decision. Conversely, a customer emphasis that is too strong is seen as having some drawbacks, as the existing customers are often not in the best position to offer guidance regarding future innovations. The case company has taken cautious steps in opening its innovation process to partners and other parties. IPR issues are regarded as one of the main challenges for the successful creation of innovations in cooperation with other parties. IPR issues have become increasingly important both when considering acquisitions and selling innovations.

The principles according to which the analysed company has organised its innovation activities reflect recommendations in the literature in many respects. First, the innovation activities are in part implemented separately from other organisational activities. Innovations are given room to develop instead of forcing them to strictly follow the processes and culture of mainstream activities. The role of the established Innovation Unit, similarly as the innovation hub concept by Leifer et al. (2001) separates innovation processes for radical and incremental innovations and helps in managing the interface between the innovation project and the rest of the organisation 
to allow necessary degree of freedom to nurture radical innovation and consider funding opportunities. The arrangements are in line with the literature (Burgelman and Sayles, 1986; Christensen, 1997; Tidd and Taurins, 1999). The innovation Unit in line Leifer et al. (2001), is responsible for the early stages of the innovation process and acts as a knowledge centre for innovation activities. The Innovation Unit also corresponds with Slater et al. (2014) who have recognised the importance of radical innovation development process and see the organisational characteristics to have an important relationship to radical innovation process. This study support the view and provide new perspectives by particularly emphasising separating the innovation process for radical innovations and those of incremental nature as the logic of core operations do not necessarily support nurturing radical innovations. In line with Slater et al. (2014) also this study recognises the influence of organisational culture on radical innovation. Separate innovation unit, or process is necessary for developing radical innovations to alleviate the tension caused by the need for control, typical for company key processes, and the need for flexibility necessitated by innovation activities. This notion is in line with the competing values approach (Quinn and Rohrbaugh, 1983) and corporate culture considerations in the organisational context (Deshpandé et al., 1993). This study pointing how an innovation unit providing necessary degrees of freedom, and the necessity of adequate linkages, to the core business favouring the development of radical innovations is in line with earlier research of Koberg et al. (2003) who has found the environmental dynamism and intrafirm linkages to positively affect the radical innovation frequency. The organisational processes and structures link to the perceived environmental dynamism, supporting separate organisational structures for radical and incremental innovation, increasing virtual dynamism. Separating innovation processes tackles the challenge of maintaining relentless innovation and avoiding attitudes of complacency and invulnerability, typical side-products of managing successful core business and protecting profits. This is in line with Tellis et al. (2009) by addressing aspects of corporate culture, ones that would hinder radical innovation.

The findings of this study support previous discussion on the selection of projects in terms of the three clusters identified by Bessant et al. (2010), enable, engage and experiment. The separation of innovation processes acts as an enabler to tackle the inability of company key processes to cope with more risky innovations. The separate innovation unit aims to allow the innovations to develop further to show the potential. This study provides new to the literature by attempting to describe the practical realisation of a separate innovation process and related selection of projects. In line with Bessant et al. (2010), this study is open for different incubation mechanisms. The findings of this study also indicate an alternative evaluation and measuring criteria, and funding structure to benefit discontinuous innovation. The presented practical realisation is in line with Bessant et al. (2010) in terms of engaging by providing structures that enable mobilising entrepreneurship. The findings, however, do not fully reveal how the role of tools and methodologies support the bridge building to/from outside the box as emphasised as experimenting by Bessant et al. (2010). Indications of decision-making being supported before commitment, however, indicates experimenting, even though the mechanisms behind the used tools is not revealed. The findings on the use of corporate funding as the model for selecting and funding projects supports Rice et al. (1998) by promoting the venture model as a mechanism relating to reviewing and funding proposals. The findings also appreciate that other mechanisms exist and provides additional value by combining the venturing approach with the separation of innovation processes. 
In terms of funding new initiatives, the case company utilises the corporate venture model as the basis for its innovation process. However, the funding of innovations is not as independent of the mainstream business as recommended in the literature (e.g., Thornhill and Amit, 2000; Wolcott and Lippitz, 2007). Rice et al. (2000) go even further by proposing a true venture capitalist model to be used for managing innovations inside companies.

The analysed company has not limited its innovation activities to include only the early part of the development process, but it focuses the innovation process on the early stages of innovation. The company has defined early stages of innovation rather well; however, it has not thoroughly described later phases of innovation development and commercialisation outside of the organised product development process. The content is similar to descriptions in the literature under the term of fuzzy front-end phase (e.g., Khurana and Rosenthal, 1997; Koen et al., 2001). This study, therefore, supports the earlier literature on the benefits of new ideas emerging from the early stages (e.g. De Bretani and Reid, 2011). The early stages are linked in particular to the innovation process via the selection of ideas to be taken further. This study shows that the early stages have a role even if the innovation process is organised, as opposed to Frishammar et al.'s (2011) view that there is a role for the fuzzy front end when the innovation process is lacking. The linkages being in idea management supports research by Van den Ende et al. (2014).

The case company has clear development paths for transferring innovations into product development and product/solution portfolio management processes. This type of distinction between front-end innovation activities and product development is supported by Veryzer (1998). However, when the utilisation of the innovation requires building new partnerships or selling innovations to other parties through spin-offs or the sale of IPR, the development work is conducted in an ad hoc manner. Hence, the company does not appear to have very systematic, inside-out innovation practices, even though some initiatives are indicated.

The case company is familiar with openness issues, but they are managed in the old context, with an emphasis on the existing business partners, while IPR considerations tend to focus more on protecting the company's technology rather than profiting from it. In particular, close customer cooperation poses a risk in terms of the failure to recognise the value in new concepts due to an attachment to existing customers and products. Moreover, systematising innovation internally while allowing external input may not, however, be enough for truly radical innovation to take place if the company falls into the trap of believing that innovation must reside primarily within it.

The case company is fully aware that the current customers are not always in the best position to give guidance regarding innovation activities. Moreover, Christensen (1997) has noted that a strong customer focus has its drawbacks and impedes the possibilities of identifying radical innovations. Company operations that are developed to serve existing customers are seen to easily hinder the development of radical innovations.

The management mentality acts as a strong impediment, especially when creating innovations that require business models that differ from the current ones (e.g., Prahalad and Bettis, 1986; Tripsas and Gavetti, 2000). The case company has attempted to overcome this by recruiting heterogeneous in-house experts and decision-makers to evaluate radical innovations. This type of evaluation and idea refinement is also recommended in the literature (Govindarajan and Trimble, 2005; Hamel, 2000; Hamel and Prahalad, 1994). However, having systematised innovation may not be sufficient if the company does not have the capacity to process the 
innovations coming into the pipeline (e.g. Chesbrough, 2017), and it appears that the analysed company is, to some extent, falling into this trap.

By applying a fail fast and cheap policy, the company is attempting to quickly identify whether innovations have potential before investing in product development activities. Even though this policy is in line with the literature regarding attempts to avoid making heavy investments in the early stages, it does not leave much room for learning through experiments, as emphasised by several authors (Christensen, 1997; Govindarajan and Trimble, 2005; Markides, 1999; McGrath and MacMillan, 1995). Overlapping in regard to organising innovations across the innovation unit, research, and product development may also hinder the possibilities for radical innovation should the ideas appear through the wrong channel as ideas are having to compete for funding.

The case company is large and is, therefore, interested only in innovations that are expected to bring in at least half a billion Euros in annual revenues after a few years. While this is understandable for a company that is used to managing large businesses, the case company easily excludes innovations that initially seem small but which may prove bigger later on. The literature has recommended having more patience with innovations that may seem small in the beginning (Christensen, 1997; Govindrajan and Trimble, 2005; Markides, 1999). The company that attempts to calculate a business case too early may exclude many potential innovations.

This study contributes to previous studies by exploring of how radical and incremental innovations are separated and managed, and by presenting an example of the selection and funding of projects in an established company that is attempting to systematise its innovation practices.

\section{Conclusion}

In order to secure its future success, a company needs to be simultaneously innovative and effective in its existing business. Practical ways of managing radical innovations are needed while ensuring compatibility with the existing business processes. This study analyses the practical implementation of the innovation activities of a leading telecom company by clarifying the organisation's development activities in general and thoroughly scrutinising its process for managing radical innovations.

The literature on the practical solutions for comprehensive innovation management appear to be relatively scarce; yet, versatile viewpoints for managing radical innovations are discussed. The analysed company has separated radical and incremental innovations to allow a degree of freedom for the development of radical innovations, while incremental innovations better fit in with the logic of core operations. The company utilises a dedicated separate process for handling radical innovations. This innovation process is linked to other company processes. The company has a separate Innovation unit that is responsible for managing and promoting radical innovations. The innovation process includes four sequential phases: idea generation, proposal preparation, idea verification, and the optional field trial. The corporate venturing model approach has been used as the basis for establishing the innovation process. Decision-making resembles traditional venture capitalist practices, including the assessment of business plans and decisions regarding funding. In order to ensure compatibility with other development processes, key personnel from different parts of the organisation are involved in refining and evaluating the ideas. Key personnel involvement also improves the commitment and acceptance of new ideas. Comprehensive innovation management provides systematisation and may support standardising decision-making, but it does 
not come without challenges. The possibility exists that many potential innovations are ignored while some benefits are gained from other perspectives.

This study illustrates one functional way of organising and managing innovations in a large established company in practice. Hence, the managers who are responsible for innovation activities may benefit from this example when having to contemplate how to organise the management of radical innovation in their companies. The presented example may also help companies to avoid potential pitfalls. The presented way of managing radical innovations includes a description of how the innovation process is linked to other processes. Consequently, companies do not need to make major changes to their other established activities. The managers ought to realise that some challenges will remain and some new ones will emerge. This article alleviates the potential problems by describing some challenges that may be expected when utilising this type of solution.

The limitations of this study include its focus on analysing the practices of a single case company that has organised its activities into processes. Moreover, the study did not address all the challenges of applying systematic innovation practices; rather, it focused more on the challenges of such practices with regard to radical innovation. The main emphasis of this study was on managing radical innovations at a certain point in time, omitting the analysis of these activities over a longer period. Potential future research could include the analysis of similar activities in a company that has organised its business into several SBUs. In addition, examining a larger number of companies in different fields and expanding the research to simultaneously analyse the functioning of all development activities, such as research, product development, and portfolio management processes, might prove interesting. An analysis of the long-term financial impacts of different organisational arrangements would also be particularly interesting.

\section{References}

Abernathy, W. and Utterback, J. (1978), "Patterns of Industrial Innovation", Technology Review, Vol. 80, No. 7, pp. 40-47.

Adams, K.A. (1983) "Needs Sensing: The Yeast for R\&D Organizations", Educational Evaluation and Policy Analysis, Vol. 5, No. 1, pp.55-60.

Alsan, A., Pasiner, I. (2009) "Profitable innovation for corporate entrepreneurship (PRINCE): cases from a multinational company", International Journal of Management Practice, Vol. 3, No. 3, pp. 209-225.

Bessant, J. Von Stamm, B., Moeslein, K.M. and Neyer, A.-K. (2010) "Backing outsiders: selection strategies for discontinuous innovation", $R \& D$ Management, Vol. 40, No. 4, pp. 345-356.

Bettis, R.A. and Prahalad C.K. (1995), "The dominant logic: retrospective and extension", Strategic Management Journal, Vol. 16, No. 1, pp. 5-14.

Biemans, W.G. (1991) "User and third-party involvement in developing medical equipment innovations", Technovation, Vol. 11, No. 3, pp.163-182. 
Bonaccorsi, A. and Lipparini, A. (1994) "Strategic partnerships in new product development: An Italian case study", Journal of Product Innovation Management, Vol. 11, No. 2, pp.134-145.

Burgelman, R. (1983), "A Process Model of Internal Corporate Venturing in the Diversified Major Firm”, Administrative Science Quarterly, Vol. 28, No. 2, pp. 223-244.

Burgelman, R. (1994), “Fading Memories: A Process Theory of Strategic Business Exit in Dynamic Environments", Administrative Science Quarterly, Vol. 39, No. 1, pp. 24-56.

Burgelman, R. and Sayles, L. (1986), Inside Corporate Innovation: Strategy, Structure and Managerial Skills, Macmillan, London.

Cagan, J. and Vogel, G.M. (2002), Creating Breakthrough Products: Innovation From Product Planning to Program Approval, Prentice Hall PTR, Upple Saddle River, NJ.

Chang, Y.-C., Chang, H.-T., Chi, H.-R., Chen, M.-H., Deng, L.-L. (2012) "How do established firms improve radical innovation performance? The organizational capabilities view", Technovation, Vol. 32, No. 7-8, pp. 441-451.

Chesbrough, H.W. (2003), Open Innovation: The New Imperative for Creating and Profiting from Technology, Harvard Business School Press, Boston, MA.

Chesbrough, H and Rosenbloom, R.S. (2002), "The role of the business model in capturing value from innovation: evidence from Xerox Corporation's technology spin-off companies", Industrial and Corporate Change, Vol. 11, No. 3, pp. 529555.

Chesbrough, H. (2017) "The Future of Open Innovation", Research-Technology Management, Vol. 60, No. 1, pp.35-38.

Chiaroni D,. Chiesa, V. and Frattini, F. (2010), "Unravelling the process from Closed Innovation to Open Innovation: evidence from mature, asset-intensive industries", R\&D Management, Vol. 40, No. 3, pp. 222-245.

Christensen, C.M. (1997), The Innovator's Dilemma: When New Technologies Cause Great Firms to Fail, Harvard Business School Press, Cambridge, MA.

Clark, K.B. (1989) "Project Scope and Project Performance: The Effect of Parts Strategy and Supplier Involvement on Product Development", Management Science, Vol. 35, No. 10, pp.1247-1263.

Cohen, S.K. and Caner, T. (2016) "Converting inventions into breakthrough innovations: The role of exploitation and alliance network knowledge heterogeneity", Journal of Engineering and Technology Management, Vol. 40, pp. 29-44.

Comer, J.M. and Zirger, B.J. (1997) "Building a supplier-customer relationship using joint new product development", Industrial Marketing Management, Vol. 26, No. 2, pp.203-211.

Contractor, F.J. and Narayanan, V. K. (1990) "Technology development in the multinational firm: a framework for planning and strategy", $R \& D$ Management, Vol. 20, No. 4, pp.305-322.

Cooper, R.G. (2001), Winning at New Products: Accelerating the Process from Idea to Launch, Perseus Publishing Cambridge, MA.

Covin, J.G., Garrett Jr., R.P., Kuratko, D.F. Shepherd, D.A. (2015) "Value proposition evolution and the performance of internal corporate ventures", Journal of Business Venturing, Vol. 30, No. 5, pp. 749-774.

Dahlander, L. and Gann, D.M. (2010), “How open is innovation?", Research Policy, Vol. 39, No. 6, pp. 699-709. 
De Brentani, U. Reid, S.E., (2011) "The Fuzzy Front-End of Discontinuous Innovation: Insights for Research and Management", Journal of Product innovation management, Vol. 29, No. 1, pp. 70-87.

Deshpandé, R., Farley, J.U. and Webster, F. (1989), "Corporate Culture, Customer Orientation, and Innovativeness in Japanese Firms: A Quadrad Analysis", Journal of Marketing, Vol. 57, No. 1, pp.23-37.

Dodgson, M., Gann, D. and Salter, A. (2005), Think, Play, Do: Innovation, Technology, and Organization, Oxford University Press, New York, NY.

Dodgson, M., Gann, D. and Salter, A. (2008), The Management of Technological Innovation: Strategy and Practice (2nd ed.), Oxford University Press, New York, NY.

Doz, Y. and Kosonen, M. (2010), "Embedding Strategic Agility: A Leadership Agenda for Accelerating Business Model Renewal", Long Range Planning, Vol. 43, No. 2-3, pp. 370-382.

Eisenhardt, K.M. (1989) "Building theories from case study research, Academy of Management Review, Vol. 14, No. 4, pp. 532-550.

Ettlie, J.E., Bridges, W.P. and O'Keefe, R.D. (1984) "Organization Strategy and Structural Differences for Radical Versus Incremental Innovation", Management Science, Vol. 30, No. 6, pp.682-695.

Forés, B. and Camisón, C. (2016) "Does incremental and radical innovation performance depend on different types of knowledge accumulation capabilities and organizational size?", Journal of Business Research, Vol. 69, No. 2, pp. 831848.

Francis, D. and Bessant, J. (2005), "Target innovation and implications for capability development", Technovation, Vol. 23, No. 3, pp. 171-183.

Frishammar, J., Floren, H., Wincent, J. (2011) "Beyond Managing Uncertainty: Insights From Studying Equivocality in the Fuzzy Front End of Product and Process Innovation Projects", IEEE Transactions on Engineering Management, Vol. 58, No. 3, pp. 551-563.

Gassmann, O., Schweitzer, F. (2014) "Management of the fuzzy front-end of innovation", Springer International Publishing, Switzerland

Gawer, A. and Cusumano, M. (2002), Platform Leadership: How Intel, Microsoft and Cisco Drive Industry Innovation, Harvard Business School Press, Boston.

Govindarajan, V. and Trimble, C. (2005), "Building Breakthrough Business Within Established Organizations", Harvard Business Review, Vol. 83, No. 5, pp. 58-68.

Green, S.G., Gavin, M.B. and Aiman-Smith, L. (1995) "Assessing a multidimensional measure of radical technological innovation", IEEE Transactions on Engineering Management, Vol. 42, No. 3, pp.203-214.

Hamel, G. (2000), Leading the Revolution, Harvard University Press Cambridge, MA.

Hamel, G and Prahalad, C.K. (1994), Competing for the Future, Harvard Business School Press Boston, MA.

Herstatt, C. and von Hippel, E. (1992) "From experience: Developing new product concepts via the lead user method: A case study in a "low-tech" field", Journal of Product Innovation Management, Vol. 9, No. 3, pp. 213-221.

He, Z-L and Wong, P-K (2004), "Exploration vs. Exploitation: An Empirical Test of the Ambidexterity Hypothesis", Organization Science, Vol. 15, No. 4, pp. 481494.

Henderson, R.M. and Clark, K.B. (1990), "Architectural Innovation: The Reconfiguration of Existing Product Technologies and the Failure of Established Firms", Administrative Science Quarterly, Vol. 35, No. 1, pp. 9-30. 
Henderson, R. (1993) "Underinvestment and Incompetence as Responses to Radical Innovation: Evidence from the Photolithographic Alignment Equipment Industry", The RAND Journal of Economics, Vol. 24, No. 2, pp.248-270.

Johnson, M.W., Christensen, C.M. and Kagerman, H. (2008), "Reinventing Your Business Model", Harvard Business Review, Vol. 86, No. 12, pp. 50-59.

Khurana, A. and Rosenthal, S.R. (1997), "Integrating the Fuzzy Front-end New Product Development", MIT Sloan Management Review, Vol. 38, No. 2, pp. 103 120.

Kinnunen, T, Pekuri, A., Haapasalo, H. and Kuvaja, P. (2011), "Business case analysis in new product development", Global Journal of Management and Business Research, Vol. 11, No. 2, pp. 49-55.

Koberg, C.S., Detienne, D.R. and Heppard, K.A. (2003) "An empirical test of environmental, organizational, and process factors affecting incremental and radical innovation", The Journal of High Technology Management Research, Vol. 14, No. 1, pp.21-45.

Koen P., Ajamian, G., Burkart, R, Clamen, A., Davidson, J, D’Amore, R., Elkins, C., Herald, K., Incorvia, M., Johnson, A., Karol, R., Seibert, R., Slavejkov, A. and Wagner, K. (2001), "Providing Clarity and a Common Language to the "Fuzzy Front-end"', Research and Technology Management, Vol. 44, No. 2, pp. 46-55.

Leifer, R, McDermott C.M., O’Connor, G.C., Peters, L.S., Rice, M. and Veryzer, R.W. (2000), Radical Innovation: How Mature Companies Can Outsmart Upstarts, Harvard Business School Press Boston, MA.

Leifer, R, O'Connor, G.C., and Rice, M. (2001), "Implementing radical innovation in mature firms: The role of hubs", The Academy of Management Executive, Vol. 15, No. 3, pp. 102-113.

March, J.G. (1991), "Exploration and Exploitation in Organizational Learning", Organization Science, Vol. 2, No.1, pp. 71-87.

McDermott, C.M. and O’Connor, G.C. (2002), “Managing radical innovation: An overview of strategic issues", Journal of Product Innovation Management, Vol. 19, No. 6, pp. 424-438.

McGrath, R.G. and MacMillan, I.C. (1995), Discovery-Driven Planning, Harvard Business Review, Vol. 73, No. 4, pp. 44-54.

Merton, R., Fiske, M. and Kendall, P. (1990), The Focused Interview: A Manual of Problems and Procedures (2nd ed.), The Free Press, New York, NY.

Meyer, M.H., Anzani, M. and Walsh, G. (2005) "Innovation and Enterprise growth", Research-Technology Management, Vol. 48, No.4, pp.34-44.

Michalski, T. (2006) "Radical innovation through corporate entrepreneurship from a Competence-Based Strategic Management perspective", International Journal of Management Practice, Vol. 2, No. 1, pp. 22-41.

Niosia, J. (1999) "Fourth-Generation R\&D: From Linear Models to Flexible Innovation", Journal of Business Research, Vol. 45, No. 2, pp.111-117.

Nobelius, D. and Trygg, L. (2002), "Stop chasing the Front-end process management of the early phases in product development process", International Journal of Product Management, Vol. 20, No. 5, pp. 331-340.

Norman, D.A. and Verganti, R. (2014) "Incremental and Radical Innovation: Design Research vs. Technology and Meaning Change", Design Issues, Vol. 30, No. 1, p.78-96.

O’Connor, C.G. and DeMartino, R. (2006), “Organizing for Radical Innovation: An Exploratory Study of the Structural Aspects of RI Management Systems in Large Established Firms", Journal of Product Innovation Management, Vol. 23, No. 6, pp. 475-497. 
O'Connor, C.G., Leifer, R., Paulson, A.S. and Peters, L.S. (2008), Grabbing Lightning: Building a Capability for Breakthrough Innovation, Jossey-Bass, San Francisco, CA.

O'Reilly, C.A. and Tushman, M.L. (2004), “The Ambidextrous Organization”, Harvard Business Review, Vol. 82, No. 4, pp. 74-81.

Prahalad, C.K. and Bettis, R.A. (1986), "The Dominant Logic: a New Linkage Between Diversity and Performance", Strategic Management Journal, Vol. 7, No. 6, pp. 485-501.

Quinn, R. and Rohrbaugh, J. (1983), “A spatial model of effectiveness criteria: Towards a competing values approach to organizational analysis", Management Science, Vol. 29, No. 3, pp.363-377.

Reid, S.E., De Brentani, U. (2004) "The Fuzzy Front End of New Product Development for Discontinuous Innovations: A Theoretical Model", Journal of Product innovation management, Vol. 21, no. 3, pp. 170-184.

Rice, M.P., Gina, C.O., Peters, L.S., Morone, J.G. (1998) "Managing discontinuous innovation", Research Technology Management, Vol. 41, No.3, pp.52-58.

Rice, M.P., O'Connor, G.C., Leifer, R., McDermott, C.M. and Standish-Kuon, T. (2000), "Corporate Venture Capital Models for Promoting Radical Innovations", Journal of Marketing Theory and Practice, Vol. 9, No. 3, pp. 1-10.

Rothwell, R. (1992), "Successful Industrial Innovation: Critical Factors for the 1990s", R\&D Management, Vol. 22, No. 3, pp. 221-239.

Saldana, J. (2009) The coding manual for qualitative researchers. Thousand Oaks, CA: Sage Publications

Santos, J., Doz, Y. and Williamson, P. (2004), “Is Your Innovation Process Global?", MIT Sloan Management Review, Vol. 45, No. 4, pp. 31-37.

Shaw, B. (1988) "Gaining added value from centres of excellence in the UK medical equipment industry", $R \& D$ Management, Vol. 18, No.2, pp.123-130.

Shrage, M. (1999), Serious Play: How the World's Best Companies Simulate to Innovate, Harvard Business Review Press, Cambridge, MA.

Slater, S.F., Mohr, J.J. and Sengupta, S. (2014) "Radical Product Innovation Capability: Literature Review, Synthesis, and Illustrative Research Propositions", Journal of Product Innovation Management, Vol. 31, No. 3, pp.552-566.

Stasch, S.F., Lonsdale, R.T., LaVenka, N.M. (1992) "Developing a Framework for Sources of New Product Ideas", Journal of Consumer Marketing, Vol. 9, No. 2, pp.5-15.

Thanasopon, B., Papadopoulos, T., Vidgen, R. (2016) "The role of openness in the fuzzy front-end of service innovation",Technovation, Vol. 47, pp. 32-46.

Tellis, G.J., Prabhu, J.C. and Chandy, R.K. (2009) "Radical Innovation Across Nations: The Preeminence of Corporate Culture", Journal of Marketing, Vol. 73, No. 1, pp.3-23.

Thornhill, S. and Amit, R. (2000), “A Dynamic Perspective of Internal Fit in Corporate Venturing", Journal of Business Venturing, Vol. 16, No. 1, pp. 25-50.

Tidd, J. (2001), "Innovation management in context: environment, organization and performance", International Journal of Marketing Reviews, Vol. 3, No. 3, pp. 169-183.

Tidd, J. and Bessant, J. (2009), Managing Innovation: Integrating Technological, Market and Organizational Change (4th ed.), Wiley, Chichester.

Tidd, J. and Taurins, S. (1999), "Learn or Leverage? Strategic Diversification and Organizational Learning Through Corporate Ventures", Creativity and Innovation Management, Vol. 8, No. 2, pp. 122-129. 
Tikkanen, H., Lamberg, J.-A., Parviainen, P. and Kallunki, J.-P. (2005), “Managerial cognition, action and the business model of the firm", Management Decision, Vol. 43, No. 6, pp. 789-809.

Tripsas, M. and Gavetti, G. (2000), "Capabilities, Cognition, and Inertia: Evidence from Digital Imaging”, Strategic Management Journal, Vol. 21, No. 10-11, pp. 1147-1161.

Trott, P. (2002), Innovation Management and New Product Development (2nd ed.), Pearson Education Limited, Harlow.

Trott, P. and Hartmann, D. (2009), “'Why Open Innovation' Is Old Wine in New Bottles", International Journal of Innovation Management, Vol. 13, No. 4, pp. 715-736.

Tushman, M. and Anderson, P. (1986), "Technological Discontinuities and Organizational Environment", Administrative Science Quarterly, Vol. 31, No. 3. pp. 439-56.

Utterback, J.M. and Abernathy, W.J. (1975) "A dynamic model of process and product innovation", Omega, Vol. 3, No. 6, pp.639-656.

Utterback, J.M. and Suárez, F.F. (1993) "Innovation, competition, and industry structure", Research Policy, Vol. 22, No. 1, pp.1-21.

Utterback, J.M. (1994), Mastering the Dynamics of Innovation, Harvard Business School, Boston, MA.

van den Ende, J., Frederiksen, L., Prencipe, A. (2014) "The Front End of Innovation: Organizing Search for Ideas", Journal of Product Innovation Management, Vol. 32, No. 4, pp. 482-487.

von Hippel, E. (1988), The Sources of Innovation, Oxford University, New York.

Veryzer, R.W. (1998), "Discontinuous Innovation and the New Product Development Process", Journal of Product Innovation Management, Vol. 15, No. 4, pp. 304321.

Wolcott, R.C. and Lippitz, M.J. (2007), "The Four Models of Corporate Entrepreneurship", MIT Sloan Management Review, Vol. 49, No. 1, pp. 74-82.

Zhang, Q. and Doll, W.J. (2001), "The fuzzy front-end and success of new product development: a causal model", European Journal of Innovation Management, Vol. 4, No. 2, pp. 95-112. 

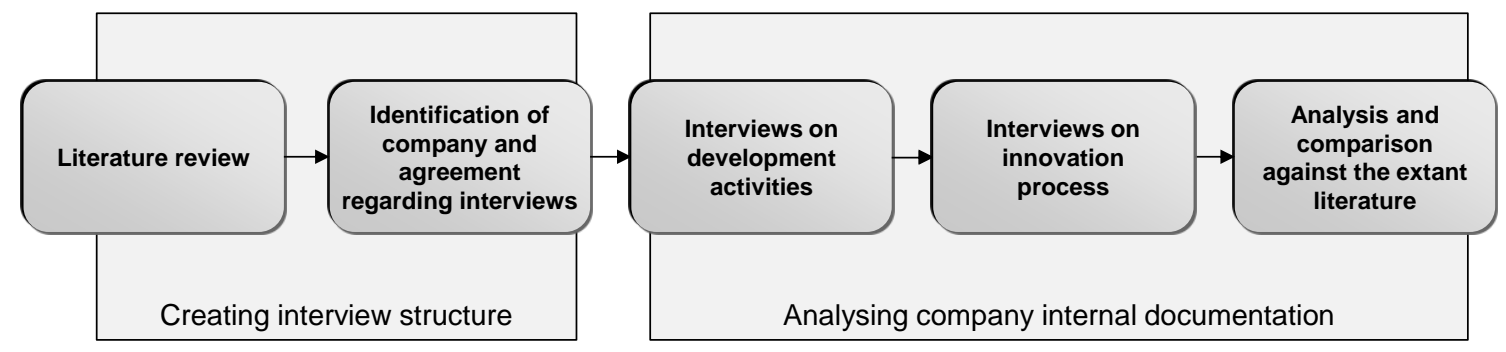

Figure 1. Research process

Product/solution portfolio management process

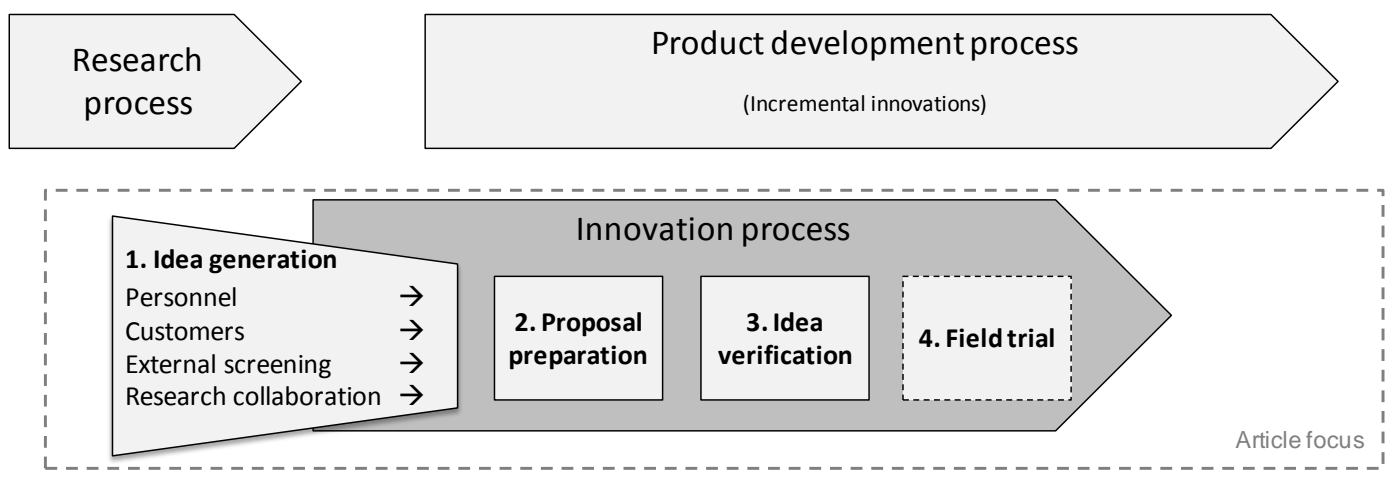

Figure 2. Innovation-related processes in the case company 
Table 1. Prioritisation criteria for new ideas

\begin{tabular}{lll}
\hline Predictions & Description & $\begin{array}{l}\text { Scoring } \\
(\mathbf{1 / 3 / 5})\end{array}$ \\
\hline Attractiveness & $\begin{array}{l}\text { Weight } \\
(\mathbf{\%})\end{array}$ \\
Market size & Revenue potential in 5 years \\
Growth & Estimated market growth rate \\
Market risk & Risks, sensitivity, prediction accuracy \\
Market share & Expected market penetration/share \\
Profitability & Expected gross/net profit \\
Sustainability & Revenue continuity, competitive advantage \\
Required investment & Investments before revenues, req. asset base \\
Feasibility & \\
Enabling disruptions & Capabilities of utilising disruptions \\
Entry barriers & Regulations/technology/IPR/customers \\
Capabilities & Internal assets/capabilities \\
Business model & Compatibility with existing business \\
Customer access & Direct access, credibility \\
Differentiation & Position compared to competitors \\
Time to revenue & \\
Market timing risk & Risks, sensitivity, adoption rate predictability \\
Investment \& asset needs & Req. investments, req. asset base \\
Capability acquisition & Assets/capabilities, partners \\
Entry barriers & Barriers, req. localisation \\
Customer access & Direct access, credibility, req. resellers \\
\end{tabular}

Table 2. Challenges encountered in relation to innovation activities

\begin{tabular}{ll}
\hline Issue & Challenge \\
\hline $\begin{array}{l}\text { Idea generation and } \\
\text { screening }\end{array}$ & Burdensome screening and refining process for new ideas \\
& Employees do not have enough time to promote their ideas
\end{tabular}




\begin{tabular}{ll}
\hline Decision-making & First evaluation too heavily dependent on individual evaluators \\
& Balancing risk-taking and certainty in decision-making \\
& Criteria for innovations depend on economic situation \\
Customer cooperation & Obtaining customer commitment \\
& $\begin{array}{l}\text { Identifying hidden risks related to customer involvement } \\
\text { Strong customer focus may hinder innovations benefitting new business } \\
\text { sectors } \\
\text { IPRs }\end{array}$ \\
\hline
\end{tabular}

